Orbis Tertius, vol. XXIII, $\mathrm{n}^{\circ}$ 28, e094, diciembre 2018. ISSN 1851-7811 Universidad Nacional de La Plata

Facultad de Humanidades y Ciencias de la Educación

Centro de Estudios de Teoría y Crítica Literaria

\title{
Chicas muertas de Selva Almada. Nuevas formas de la memoria sobre el femicidio en la narrativa argentina
}

\section{María Celeste Cabral* \\ * Universidad Nacional de La Plata, Argentina}

Cita sugerida: Cabral, M. C. (2018). Chicas muertas de Selva Almada. Nuevas formas de la memoria sobre el femicidio en la narrativa argentina. Orbis Tertius, 23(28), e094. https://doi.org/10.24215/18517811e094 


\title{
Chicas muertas de Selva Almada. Nuevas formas de la memoria sobre el femicidio en la narrativa argentina
}

\author{
por María Celeste Cabral \\ (Universidad Nacional de La Plata)
}

\begin{abstract}
Resumen:
Los episodios traumáticos del pasado dictatorial ocuparon en la literatura argentina un espacio central. Chicas muertas de Selva Almada inicia el diálogo con ese corpus en dos planos: por un lado señala la invisibilidad de los feminicidios durante el retorno de la democracia. Por otra parte, el texto recupera la pregunta sobre cómo narrar la violencia extrema que-iniciada en el aforismo de Theodor Adorno (1955) - recorre las discusiones en torno a las formas del relato sobre el pasado reciente. Este trabajo explora en el texto de Almada las nuevas memorias sobre el feminicidio que emergen en el campo literario en un contexto de profunda sensibilización social sobre el tema. Palabras clave: memoria - testimonio - literatura argentina - femicidio - Selva Almada.
\end{abstract}

\section{Abstract:}

Traumatic episodes of the recent dictatorial past have had a central space in Argentine literature. Selva Almada's Chicas muertas initiates a dialogue with literary works that address dictatorship in two levels: first, Almada points to the invisibility of the crimes against women under the return to democracy in 1982; Then, Chicas muertas returns to Theodor Adorno's question on how to narrate extreme violence, and by doing so engages with discussions on forms of narrating the recent past. This article explores how Almada's text works with the new forms of the memory of femicides which emerged in the literary field in the context of a profound social awareness on that issue.

Keywords: Memory - Testimony - Argentine Literature - Femicide - Selva Almada.

Dicen que para recordar hay que olvidar. No hay ningún recuerdo que se pueda traer a la memoria si no se fue al olvido. Y acá no hay ni olvido ni perdón. Ni muertos. Hay eufemismos. Desaparecidos. Casi cuarenta años después y los desaparecidos siguen sin morirse. [...] "Néstor no se murió", "Evita vive en el corazón de su pueblo", "Luca’s not dead”. En este país tampoco se mueren los muertos. Entonces ¿Cómo se inscriben en la trama social las muertes violentas? Las víctimas del gatillo fácil, los muchachitos que son linchados por una turba, los que se partieron en mil pedazos con las bombas de la AMIA y la Embajada de Israel, ¿están muertos? Cuando no hay justicia, ¿los muertos no se mueren? ¿Los muertos sin justicia son una versión política del "alma en pena"?

Raquel Robles, "En esta casa no se muere nadie”.

A esta pregunta de Raquel Robles sobre las representaciones de la impunidad en Argentina, Chicas muertas de Selva Almada añade las víctimas de femicidio, y agrega un nuevo eslabón: su libro plantea cómo narrar la continuidad entre la violencia del pasado y del presente, desde el extremo del asesinato hasta las formas más sutiles de la dominación patriarcal.

El libro reconstruye las vidas de Sarita Mudín, Andrea Danne y María Luisa Quevedo, jóvenes víctimas de feminicidios ocurridos en diferentes localidades del interior de Argentina durante los años $80 .{ }^{1}$ El relato de la vida de esas mujeres utiliza diversos recursos que incluyen entrevistas a familiares y amigos, fragmentos narrativos, el trabajo con fuentes periodísticas y judiciales, y un uso particular de la primera persona que da cuenta del proceso de investigación protagonizado por la cronista, intercalados con la rememoración de diversos episodios de violencia contra las mujeres provenientes de la propia experiencia de la narradora o de rumores circulantes en el pueblo donde ella creció. El resultado es un relato polifónico que construye una "literatura de provincia" (Sarlo 2012) como un paisaje sonoro, con una voz narrativa fuerte que acude a repertorios del testimonio y la crónica en clave subjetiva (Sarlo 2005).

El presente artículo propone interpretar el texto de Selva Almada desde la perspectiva de los estudios sobre memoria y deslindar algunos de los elementos que desarticulan los regímenes de verdad y los márgenes de lo decible según establecen los protocolos y tradiciones específicas de ciertos géneros literarios puestos en tensión, como la crónica y el testimonio. En esta clave de lectura, el texto renueva los repertorios discursivos de la memoria para referirse a los casos de violencia contra las mujeres con una especificidad propia. Estas 
nuevas formas de la memoria, sin embargo, sólo fueron posibles una vez que las condiciones sociales de escucha habilitaron el surgimiento de nuevos testimonios que visibilizaron las formas naturalizadas de la violencia contra las mujeres. La emergencia de estas nuevas memorias abocadas al femicidio en Argentina, entre las que se incluye Chicas muertas, es un fenómeno que excede el campo literario e incluye otras formas artísticas e intervenciones culturales en el contexto de una profunda sensibilización social sobre el tema.

${ }^{2}$ Cabe preguntarse cuáles son las características específicas de estas memorias colectivas, qué similitudes y diferencias guardan respecto de otros momentos del testimonio en Argentina, qué actores y fenómenos sociales contribuyeron a su conformación. El presente análisis constituye una propuesta para profundizar ese camino de investigación.

\section{Hacia una genealogía de las formas de la memoria: narrativa argentina y dictadura}

El corpus de las narrativas sobre la última dictadura constituye un punto de partida para la reflexión sobre el lugar de Chicas muertas y sus vínculos con el testimonio, las continuidades que pueden trazarse y las nuevas formas que incorpora a los "trabajos de la memoria" en Argentina (Jelin 2002).

Por un lado, el desarrollo del género testimonial en Argentina se inicia a mediados de los ochenta abocado al trauma social consecuencia de la represión y el terrorismo de estado durante la última dictadura, con las investigaciones de la CONADEP que dieron origen al informe Nunca Más y la edición del Diario del Juicio a las juntas militares en 1985. Luego las leyes de Obediencia Debida y Punto Final determinaron hacia los años noventa un nuevo contexto de impunidad que hizo posible la circulación de las confesiones públicas de algunos de los represores. Al mismo tiempo, la irrupción en escena de la generación de HIJOS recuperaba la participación política de los desaparecidos a la vez que surgía el registro de las llamadas "memorias militantes" que recuperaban la historia de los sobrevivientes de la lucha armada desde la clave subjetiva que sería fuertemente debatida a partir de las objeciones planteadas por Beatriz Sarlo en Tiempo pasado (2005).

Por otra parte, de modo paralelo a los avatares del género testimonial, los recorridos de la crítica literaria mostraron la sistematicidad entre los regímenes de memoria sobre la violencia política del pasado reciente y su correlato en las estéticas literarias que acompañaron esos cambios sociales. Con diversos matices entre los autores que abordaron el tema, es posible recortar tres momentos principales en la periodización. En primer lugar, durante el período de la dictadura, formas vanguardistas como la elipsis narrativa, la alusión metafórica y la escritura fragmentaria -surgidas durante los años sesenta- se volvieron estratégicas en el contexto de censura. De acuerdo con Sarlo (1987), en novelas como Respiración artificial (1980) de Ricardo Piglia, Nadie nada nunca (1980)de Juan José Saer y Pubis angelical (1979) de Manuel Puig, entre otras, el abandono de la representación realista en pos de otras estéticas habría permitido surcar la represión y a su vez dar cuenta de la experiencia límite del terrorismo de estado. Por otra parte, estas estéticas alternaron además con los usos del pasado de la novela histórica que se refería veladamente a las luchas políticas y la represión contemporáneas (Sosnowski, 1997). Durante la segunda etapa iniciada a mediados de la década del noventa, las estéticas realistas vuelven al centro de la escena. Allí Dalmaroni (2004) encuentra que en novelas como Villa (1995) y Ni muerto has perdido tu nombre (2002) de Luis Gusmán, Dos veces junio (2002) de Martín Kohan o El fin de la historia (1996) de Liliana Heker, el realismo literario en sus diferentes versiones procuró "narrar refiriendo por completo, y de modo directo, los sucesos y acciones más atroces o inenarrables" asumiendo el desafío de configurar en primera persona las voces de los militares y sus cómplices civiles en el ámbito privado y cotidiano de la rutina represiva (2004: 159). Por último, una tercera etapa tiene como punto de inflexión el estallido social del 19 y 20 de diciembre de 2001. Este episodio coincide con el momento de emergencia de las narrativas de la segunda generación de la posdictadura. De acuerdo con Elsa Drucaroff (2011), los nacidos a partir de 1970 -cuya experiencia de la dictadura transcurrió durante la infancia, sean o no hijos/as de desaparecidos/as, presos/as o asesinados/as- aportan a la nueva narrativa argentina un 
abordaje de la violencia armada que rompe el "tabú del enfrentamiento", dejando de lado representaciones de la generación militante en clave de víctimas inocentes y dando lugar en cambio al "entusiasmo, la alegría joven de la militancia o el heroísmo de muchos activistas que participaron en la lucha armada" (2011: 195). ${ }^{3}$ Por otra parte, si durante los noventa el contexto de impunidad había favorecido la emergencia de estéticas realistas, a partir del 2001 -y más fuertemente con el avance del proceso de juzgamiento de los represoresla narrativa de la segunda generación se caracteriza por la "ausencia de sentido" (Gatti 2011), en tanto sus autores/as producen el desplazamiento del tono solemne a formas de la ironía, la parodia o el humor. En esta clave de lectura es posible acercarse a obras como las de Raquel Robles, Félix Bruzzone, Mariana Eva Pérez o Pola Olloixarac entre otros/as. En esta etapa el uso de una estética corrosiva de los sentidos sobre el pasado reciente se combina con un registro autoficcional (Alberca 2007) que en sus diferentes matices pone en primer plano las memorias de estas infancias clandestinas, combatientes, travestidas, y su impacto en la experiencia del presente. En obras como las de Laura Alcoba, Leopoldo Brizuela, Julián López o Marta Dillon se observa una recuperación de las vidas de los/as militantes en una clave despojada de su dimensión heroica, políticamente incorrecta, enfocada en la vida privada y familiar, la dimensión afectiva, el pasado anterior al ingreso a la vida política. Resulta de suma importancia señalar el lugar central que cobra la pregunta sobre el impacto de la violencia en la propia identidad huérfana de esta generación, asumiendo un posicionamiento propio respecto de la ausencia de los padres, que permanece equidistante entre la reivindicación-homenaje a la generación perdida y el reclamo culpabilizador por el abandono en pos de sus opciones políticas. En esta etapa la literatura se transforma en el discurso social que da por saldado el debate acerca del uso de la primera persona para referirse a la experiencia del pasado reciente, y muestra las potencialidades de explorar las huellas del impacto de la violencia en el plano subjetivo.

Chicas muertas de Selva Almada inicia el diálogo con aquel corpus literario y testimonial en dos planos, un plano formal o de las elecciones estéticas, y otro que atiende a los focos temáticos de reflexión. Respecto del segundo, en relación a los casos de femicidios investigados, la cronista sigue la huella de las continuidades con las estructuras de poder que conformaron el aparato represivo del estado. Si para el caso de María Luisa Quevedo la connivencia con el poder empresarial por parte del juez y el funcionamiento de "una policía con los vicios de la dictadura empantanaron el caso" (2014: 152), en la muerte de Sarita Mundín se evidencian las complicidades del sistema político: tras iniciarse en la prostitución, "de yirar en la ruta pasó a tener una cartera de clientes del Comité Radical. Ella y su amiga Miriam García eran militantes del partido, dos muchachas jóvenes y lindas que enseguida acapararon la atención de los señores mayores, de buena posición social y doble discurso" (2014: 57).

Por otra parte la autora señala el contraste entre el clima festivo de la primavera alfonsinista y la invisibilidad de los episodios de violencia hacia las mujeres. El día de la aparición del cuerpo de María Luisa en las afueras de Sáenz Peña,

en Buenos Aires, a 1107 kilómetros, a esa hora recién se apagaban los ecos de las fiestas populares por la asunción de Raúl Alfonsín [...]. En Sáenz Peña todos habían estado pendientes de la televisión que durante el sábado había transmitido en directo, por Cadena Nacional, los actos y festejos [...]. Mientras todos celebraban, los Quevedo seguían buscando a María Luisa (2014: 26).

Mientras la TV instala en la memoria oficial la versión del fin de la impunidad y el enjuiciamiento de los responsables militares, el inicio de las políticas de memoria del Estado democrático esconde bajo la alfombra los femicidios en el interior del país. Con estas historias, Almada rescata lo que Michelle Pollak (2006) llamó "memorias subterráneas", aquellas versiones sobre el pasado que sectores minoritarios de la sociedad no logran incluir en la memoria colectiva en disputa. Estos recuerdos "indecibles", "vergonzosos", que no encuentran en su momento condiciones de audibilidad, se conservan y transmiten por vías alternativas en el ámbito privado, mientras esperan el contexto propicio para emerger. Con estos testimonios el texto recupera las "memorias subterráneas" en torno a las muertes ocurridas cuando "todavía en nuestro país desconocíamos el término 
femicidio" (Almada 2014: 18) y las pone en circulación. Si los testimonios de las víctimas del terrorismo de estado lograron tempranamente ubicar su relato en el lugar de la memoria hegemónica e impulsaron exitosamente la causa de las vulneraciones en materia de derechos humanos contando inclusive con apoyo y reconocimiento internacional, por el contrario, fue necesario un período de tiempo mucho más prolongado para que las memorias sobre los femicidios encontraran condiciones de escucha social y obtuvieran un lugar en la memoria colectiva. La inexistencia de espacios colectivos de familiares y allegados a las víctimas de femicidio durante esos primeros años tiene su explicación en las propias condiciones de exclusión social de estos sectores en el marco del sistema patriarcal.

Ahora, si bien es cierto que memoria y olvido tienen temporalidades propias (Jelin 2006: 26), no es menos verdadero que la forma -esto es, el género- hace a la negociación de esas condiciones de escucha. Arfuch, en un estudio sobre las formas discursivas de la memoria, advierte que ninguna experiencia es transferible por fuera de las condiciones que el género discursivo le imprime. Las pautas formales propias de cada uno imponen pactos de lectura, presupuestos sobre la veracidad, los grados de subjetividad, la intencionalidad autoral; en síntesis, un "sistema de valoración de mundo" que incide en la recepción, la comprensión y las expectativas del destinatario (2013: 99). Almada advierte el cambio de época que permite la emergencia de aquellas "memorias subterráneas" sobre el femicidio en la posdictadura y encuentra la vía para su narración en un texto que recupera los debates que la literatura y el testimonio atravesaron en torno a la pregunta sobre “cómo narrar" la violencia. En ese sentido, resulta relevante deslindar qué elementos específicos de diferentes géneros se hacen presentes en Chicas muertas.

\section{Formas de la memoria que suplen la falta. El testimonio (im)posible y sus derivas}

El título Chicas muertas remite a los problemas del género testimonial, concretamente a las reflexiones de Giorgio Agamben acerca de las posibilidades de existencia del testimonio y del testigo (2003: 13-40). El autor recupera de Shoshana Felman la conceptualización de la shoah como un "acontecimiento sin testigos": "sobre ella es imposible dar testimonio, tanto desde el interior -porque no se puede testimoniar desde el interior de la muerte, no hay voz para la extinción de la voz- como desde el exterior, porque el outsider queda excluido por definición del acontecimiento" (Agamben 2003: 35). Nadie externo al exterminio puede comprenderlo en su radicalidad y nadie que lo experimente en primera persona hasta el final sobrevive para contarlo. Frente a esta paradoja que "pone en tela de juicio el propio sentido del testimonio y, por ello mismo, la identidad y la credibilidad de los testigos" (2003: 33), Agamben retoma de Primo Levi la idea de que todo testimonio presenta siempre una laguna, un centro vacío, una falta de la que los sobrevivientes procuran dar cuenta. Esa falta, que es la del relato de los muertos en el exterminio, impulsa el deber de testimoniar de los sobrevivientes. Afirma Levi:

Lo repito, no somos nosotros, los supervivientes, los verdaderos testigos... Los que hemos sobrevivido somos una minoría anómala, además de exigua: somos aquellos que por sus prevaricaciones, o su habilidad, o su suerte, no han tocado fondo. Quien lo ha hecho, quien ha visto a la Gorgona, no ha vuelto para contarlo, o ha vuelto mudo; son ellos, los "musulmanes", los hundidos, los testigos integrales, aquellos cuya declaración habría podido tener un significado general. Ellos son la regla, nosotros la excepción... Los que tuvimos suerte hemos intentado, con mayor o menor discreción, contar no solamente nuestro destino sino también el de los demás, precisamente el de los "hundidos"; pero se ha tratado de una narración "por cuenta de terceros", el relato de cosas vistas de cerca pero no experimentadas por uno mismo. La demolición terminada, la obra cumplida, no hay nadie que la haya contado, como no hay nadie que haya vuelto para contar su muerte (citado en Agamben 2003: 33).

Almada reconstruye su propia historia como sobreviviente al afirmar que este libro comenzó a escribirse en 1986, "cuando la chica muerta se cruzó en mi camino. Ahora tengo cuarenta años y, a diferencia de ella y de las miles de mujeres asesinadas en nuestro país desde entonces, sigo viva. Sólo una cuestión de suerte" (2014: 182). Las "chicas muertas" son aquí los "hundidos" de Primo Levi cuyas voces la narradora reemplaza. Las 
miles de mujeres asesinadas anónimamente en el transcurso de los años son el relato del testigo total que la autora se propone rescatar para las vivas. ${ }^{4}$ Como obedeciendo a un instinto de conservación, Almada incluye en el epílogo los casos de otros diez femicidios en el lapso del mes previo a que el libro entre en edición, tomados de la prensa. Como si el registro de los nombres de las víctimas fuera capaz de devolverles la voz en este testimonio colectivo.

La autora obedece al deber de memoria intercalando, entre las historias de Sarita, Andrea y Maria Luisa -testigos totales según Agamben- los relatos de situaciones protagonizadas por ella misma, de las cuales sobrevivió: haciendo dedo en la ruta un hombre quiso salir con ella, otro le ofreció tener sexo a cambio de unos pesos, otro diciendo que era ginecólogo la manoseó para explicarle cómo hacerse autocontrol. Sugiriendo la idea de que la muerte toca a unas y no a otras como fruto del azar, la autora interpela, a su vez, a la segunda persona del lector: "Mi casa, la casa de cualquier adolescente, no era el lugar más seguro del mundo, adentro de tu casa podían matarte. El horror podía vivir bajo el mismo techo que vos” (2014: 17). La voz narrativa ensaya un diálogo con las asesinadas con apelativos en segunda persona: “¿”Dónde estás Sarita? ¿Quién es la otra chica muerta?” (2014: 176). La respuesta imposible de las víctimas desencadena un conjunto de estrategias desplegadas en consecuencia para recuperar sus voces, para reconstruir el testimonio de sus vidas y sus muertes violentas.

En este ejercicio de memoria sobre los femicidios la autora acude a recursos y fuentes colindantes con otros géneros diferentes de la tradición del testimonio en Argentina. A partir del trabajo con las causas judiciales, la cobertura periodística y entrevistas a allegados a las víctimas, consigue reconstruir los casos y representarlos con un formato narrativo más cercano a la crónica o la no-ficción. Almada sigue la pista de las posibles líneas de investigación en torno a los crímenes de acuerdo con la tradición de Truman Capote y Rodolfo Walsh, entre otros. El manejo de los materiales alterna la narración en un registro narrativo con la transcripción directa de las fuentes toda vez que sirve para eludir el morbo. Por ejemplo al citar actas judiciales de las autopsias se evita la aparición de un narrador que describa los cuerpos o las escenas del crimen, privilegiando un registro que evite la revictimización.

Sin embargo, junto al régimen de verdad y el tratamiento de las fuentes propios del testimonio y la noficción, el texto incluye elementos díscolos, inapropiados a ese registro: tanto los familiares de María Luisa como el novio de Andrea Danne consultaron videntes que revelaron información importante sobre los casos. La narradora, a su vez, yuxtapone estas escenas con sus propios recuerdos de infancia de las visitas al curandero del pueblo que le curaba empachos, mal de ojo y el mal de la pata de cabra (2014: 46). Estas voces de otros personajes del lugar, tan fuera de lugar de acuerdo a los regímenes de construcción de verdad propios de la investigación del crimen, serán las que suplan el centro vacío del testigo ausente. La distancia entre la cronista y el mundo de los casos investigados se anula totalmente cuando agrega el recuerdo de las gitanas que leían la mano y a continuación introduce el personaje de "la Señora", una tarotista a la que visitará asiduamente para comunicarse con "las chicas" y conocer datos de su pasado.

La primera persona de la narradora testigo y las otras voces y fuentes se superponen componiendo un solo relato sin que esto plantee ninguna contradicción entre los diferentes regímenes de verdad: "en las cartas de tarot aparece un amante, un hombre mayor que ella. En el expediente, también. Yo lo conocí. Vivía a pocas cuadras de mi casa en la época del crimen" (2014: 112).

Además de estos personajes de sospechosa credibilidad, junto a las fuentes de información legítimas, aparece la zona dudosa del "rumor", reponiendo ese léxico provinciano que caracteriza tan bien los prejuicios aprendidos sobre el otro. Para el caso de Andrea Danne, la cronista incluye las voces de los estudiantes que tomaban el colectivo y veían a Andrea conversar con un chofer sospechado de amante, las compañeras de estudio que afirman que tenían una relación amorosa, la dueña de pensión que atestigua que se encontraban en un dormitorio. Como además el sospechoso era casado con una forastera, los parroquianos del bar 
decían que era raro, con esa inflexión que le ponían a la palabra cuando querían decir que el tipo era una fruta picada y la pareja distante era la comidilla del barrio. Cuando lo vincularon con el asesinato de Andrea, las murmuraciones crecieron como moscas encima de una osamenta (2014: 113).

Nora Catelli, que ubica en el uso del "rumor" el origen del psicoanálisis y de la literatura moderna, explica que, en su etimología, la palabra "chisme" tiene dos significados. Designa tanto la idea de cisma, división y conspiración de un sector de una comunidad contra el otro, como la idea del fragmento roto que se ha desprendido de una cosa, lo ínfimo, lo menor. La escritora explica que el "chisme" es considerado por algunos autores como una "antitaxonomía, una acumulación de informaciones no clasificables" que conforman no sólo "un saber caótico e incompleto, sino, históricamente, un arte precioso y devaluado, inmemorialmente asociado, en el pensamiento occidental, a sirvientes, homosexuales y mujeres" (2007: 79). Así el rumor o chisme en Chicas muertas de Selva Almada no es únicamente información falsa para el regodeo de entrometidos, sino que constituye también una forma de resistencia de las mujeres que procura pasar inadvertida:

Me crié escuchando a las mujeres grandes comentar escenas así en voz baja, como si las avergonzara la situación de la pobre desgraciada o como si ellas también le temieran al golpeador. Mi madre hablaba de estas historias en voz alta y con indignación y siempre era la compañera de chisme de turno la que le hacía señas para que hablara más bajo, la que nos señalaba a los niños diciendo: cuidado que hay ropa tendida... (2014: 56).

Ocultándose en el caos aparente de su forma, el rumor y la habladuría transmiten un saber como una pedagogía clandestina.

No recuerdo ninguna charla puntual sobre la violencia de género ni que mi madre me haya advertido alguna vez específicamente. Pero el tema siempre estaba presente. Cuando hablábamos de Marta, la vecina golpeada por su marido, la que a su vez descargaba sus propios puños sobre sus hijos. [...] Cuando hablábamos de Bety, la señora de la despensa que se colgó en el galponcito del fondo de su casa. Todo el barrio decía que el marido le pegaba y que le sabía pegar bien porque no se le veían las marcas. Nadie lo denunció nunca. Luego de su muerte se corrió la voz de que él la había matado y había tapado todo haciéndolo pasar por un suicidio. Podía ser. También podía ser que ella se hubiera ahorcado, harta de la vida que tenía (2014: 54 - 55).

El testimonio subterráneo de los femicidios circula allí donde nadie lo nota: en los márgenes, la memoria de las muertas se camufla en nuevas formas para ser transmitida y el relato se detiene en lo minúsculo de la violencia señalando el peligro:

Esas escenas convivían con otras más pequeñas: la mamá de mi amiga que no se maquillaba porque su papá no la dejaba. La compañera de trabajo de mi madre que todos los meses le entregaba su sueldo completo al esposo para que se lo administrara. La que no podía ver a su familia porque al marido le parecían poca cosa. La que tenía prohibido usar zapatos de taco porque eso era de puta (2014: 56).

El chisme y el rumor, como un paisaje sonoro, integran el retrato regional de esta "literatura de provincia" (Sarlo, 2013). Los mitos y arquetipos populares también son formas integradas a la vida cotidiana: prescriben la conducta de las mujeres pero ocultan la naturaleza del peligro. En lugar de la función contra hegemónica de las memorias subalternas, su intención es disciplinaria:

Desde chicas nos enseñaban que no debíamos hablar con extraños y que debíamos cuidarnos del Sátiro. El Sátiro era una entidad tan mágica como, en los primeros años de la infancia, la Solapa o el Viejo de la Bolsa. Era el que podía violarte si andabas sola a deshora o si te aventurabas por sitios desolados [...]. Nunca nos dijeron que podía violarte tu marido, tu papá, tu hermano, tu primo, tu vecino, tu abuelo, tu maestro. Un varón en el que depositaras toda tu confianza (2014: 55).

La narración traduce los trazos de la memoria al contenido del paisaje: se detiene en las noches de carnaval, el colectivo lechero, la vuelta al perro, la siesta de verano, el barullo de niños que juegan en la calle confundido en el sonido de los televisores sobre la vereda, el olor de los espirales que se mezcla al aroma de la tierra fresca después del paso del camión regador. Este paisaje entrañable ostenta sin embargo un costado siniestro cuando, 
junto a personajes inofensivos como "el fisgón", o el policía que recorre el pueblo en bicicleta, aparecen formas naturalizadas de la prostitución como "visitar a un hombre solo que a cambio ayuda con plata [...] o la empleada doméstica que fuera del trabajo se encuentra con el marido de la patrona y esos encuentros le arriman unos pesos" (2014: 59). Otras costumbres locales son en realidad violaciones colectivas, como "el juego del becerro" (2014: 67), en el que un conjunto de varones elige a un miembro del grupo para seducir a una chica y llevarla engañada a un descampado donde puedan abusar de ella y pagar con dinero su silencio. De esta manera la reconstrucción de los tres crímenes se disemina en mínimas formas múltiples de la dominación de las mujeres, formas de la violencia disimuladas en el paisaje y la costumbre local.

\section{Las nuevas formas de la memoria y el femicidio. Hacia el relato de la intimidad}

No sabía que a una mujer podían matarla por el solo hecho de ser mujer, pero había escuchado historias que, con el tiempo, fui hilvanando (Almada, 2014: 18).

Si el objetivo del testimonio es denunciar un crimen y el de la no-ficción es descubrir sus tramas ocultas, la investigación de esta cronista fracasa, se pierde en su propio derrotero, sin rumbo aparente, sugiriendo una nueva clave de lectura. En una sesión de tarot, el personaje de "la señora" dice a la narradora: "Yo creo que lo que tenemos que conseguir es reconstruir cómo el mundo las miraba a ellas. Si logramos saber cómo eran miradas, vamos a saber cuál era la mirada que ellas tenían sobre el mundo, ¿entendés?” (2014: 109). Lo llamativo de esta frase es que la segunda parte de la condicional debería ser "vamos a saber quién las asesinó, cómo, por qué". Al considerar este objetivo de "saber cuál era la mirada que ellas tenían sobre el mundo" como una clave de lectura, surgen las reflexiones de Holroyd sobre el trabajo del biógrafo que, como el arqueólogo, busca en las piezas abandonadas del pasado fragmentos de la vida que quiere reconstruir, a quien "una búsqueda obsesiva, casi detectivesca, lo lleva a abismarse en archivos, manuscritos, borradores, cartas, documentos, retratos, objetos atesorados, ámbitos -la casa, el jardín-, a recorrer los mismos senderos [que el personaje biografiado] para mirar las mismas cosas" (Arfuch 2013: 48).

Este "recorrer los mismos senderos para mirar las mismas cosas" del biógrafo, del investigador y del arqueólogo, tan parecido al "saber cuál era la mirada que ellas tenían sobre el mundo", se acerca a otro concepto de Holroyd, que es el de la biografía como una "intimidad entre extraños" (Arfuch 2013: 49). En tanto exposición de una vida privada que causa atracción, una biografía exitosa debe saber crear una zona de intimidad cómplice entre biógrafo, biografiado y lector. En Chicas muertas, Selva Almada introduce al lector en la cocina de su escritura para acercarnos no sólo a las biografiadas, sino también a ella misma. El lector la acompaña en sus recorridos, sus dudas, las entrevistas donde el relato del otro se desarma, las escenas en que tiene miedo, hambre, calor, se enoja o está cansada. La intimidad de la narradora con el espacio provinciano y sus personajes le entrega los datos a los que ningún cronista podría acceder y así los relatos de chicas muertas se multiplican. En la sobremesa de un asado, su suegro recuerda el asesinato de "la Carahuni" y "enseguida alguien recuerda un caso más reciente, del 97, el de Andrea Strumberger, una muchacha de diecisiete años, estudiante de secundaria" (2014: 86). Un amigo le narra una escena donde vio a una niña prostituirse por un plato de comida en la Terminal de colectivos. La hermana de Sarita, en la intimidad de la entrevista, le confiesa lo que no aparece en la causa judicial: un funcionario le mostró un par de huesos pelados y unas piezas dentarias y le hizo firmar un oficio que decía que ese era el cuerpo de su hermana. Años después la prueba negativa de ADN demostró que ese cadáver no era el de Sarita, y las muertes siguen multiplicándose ante el horror de la cronista: "hay otra mujer muerta a la que nadie reclama o a la que todavía su familia la sigue buscando; ese atadito de huesos que enterraron con el nombre de Sarita” (2014: 128). Cuanto más próxima se encuentra al testimonio de las muertas, nuevos relatos y nuevos restos brotan como si hubiera una condición natural en ella que los atrajera. Al visitar el baldío donde fue hallada María Luisa Quevedo, una mujer del barrio le explica que el terreno que busca se encuentra a unos metros, y el basural que está fotografiando es 
el sitio del crimen de "la Maira Tévez", asesinada por su novio de un disparo en la cabeza antes de cercenar el cuerpo en partes para ocultarlas (2014: 173).

En la primera visita a la tarotista, la Señora compara a la cronista con "La huesera", un mito cherokee de una mujer que se dedica a juntar huesos en el desierto, con los que luego arma un esqueleto y le canta con los brazos extendidos hasta que cobra vida y se transforma en una mujer, que corre como loba aullando bajo la luna (Pinkola 1996). El mito de la huesera es el de la guardiana de la memoria, que "junta y guarda todo lo que corre el peligro de perderse" (Almada 2014: 49), cuyo canto devuelve a la vida el material recobrado. Como el testigo integral que propone Primo Levi, esta cronista huesera recoge los restos de las muertas, habilita su retorno imposible desde la muerte devolviéndoles la voz, rescatando su testimonio desde el relato subterráneo para incorporarlo en la memoria colectiva que les estaba vedada.

\section{A modo de cierre}

Almada construye un texto que aúna en su escritura elementos del género testimonial, la crónica o no ficción y la narrativa, dando una respuesta novedosa al debate sobre el "cómo narrar" la violencia para el caso de los femicidios ocurridos en el interior del país desde mediados de los años ochenta. El lugar de enunciación que configura la autora es a la vez el de testigo, cronista, narradora y personaje de las historias que relata. La inscripción de este yo en lo narrado, propia de la "intimidad" de la biografía, se aproxima al uso de la primera persona de la generación de la posmemoria y se sintetiza a su vez en el arquetipo de "la huesera", como guardiana de la memoria, que vuelve a la vida los cuerpos de las mujeres, con el uso de su voz. El trabajo testimonial que realiza Selva Almada en Chicas muertas propone la configuración de nuevas formas de la memoria sobre el femicidio en la literatura argentina.

\section{ReFERENCIAS}

Adorno, Theodor (1962) [1955]. Prismas. Critica de la cultura y la sociedad, Barcelona, Ariel.

Agamben, Giorgio (2000). Lo que queda de Auschwitz. El archivo y el testigo. Horno Sacer III, Valencia, Pre-Textos. Alberca, Manuel (2007). El pacto ambiguo. De la novela autobiográfica a la autoficción, Madrid, Biblioteca Nueva. Almada, Selva (2014). Chicas muertas, Buenos Aires, Mondadori.

Arfuch, Leonor (2013). Memoria y autobiografia. Exploraciones en los limites, Buenos Aires, FCE.

Basile, Teresa (Coordinadora) (2015). Literatura y violencia en la narrativa latinoamericana reciente, La Plata, Universidad Nacional de La Plata. Facultad de Humanidades y Ciencias de la Educación. (Colectivo crítico, 2) Disponible en: http://libros.fahce.unlp.edu.ar/index.php/libros/catalog/book/37

Catelli, Nora (2007). En la era de la intimidad. Seguido de: El espacio autobiográfico, Rosario, Beatriz Viterbo.

Dalmaroni, Miguel Ángel (2004). La palabra justa: Literatura, crítica y memoria en la Argentina, 1960-2002, Melusina, Santiago de Chile: RIL.

Drucaroff, Elsa (2011). Los prisioneros de la torre. Politica, relatos y jóvenes en la postdictadura, Buenos Aires, Emecé.

Gatti, Gabriel (2011). "El lenguaje de las víctimas: silencios (ruidosos) y parodias (serias) para hablar (sin hacerlo) de la desaparición forzada de personas", en Universitas humanistica, $\mathrm{n}^{\circ} 72$ julio-diciembre), pp. 89-109.

Jelin, Elizabeth (2002). Los trabajos de la memoria, Buenos Aires, Siglo XXI.

Lagarde y Marcela de los Ríos (2006 [1976]). “Prólogo” e “Introducción”, en Diana Russell y Jill Radford, Feminicidio: la política del homicidio de mujeres, México, UNAM, pp. 15-27.

Lagarde y de los Ríos, Marcela (2008). “Antropología, feminismo y política. Violencia feminicida y derechos humanos de las mujeres”, en Margaret Bullen y Carmen Diez Mintegui (Coords Actas del XI Congreso de Antropología de la Asociación Vasca de Antropología de la UPV: retos teóricos y nuevas prácticas, Donostia, Ankulegi Antropologia Elkartea, pp. 209-239. 
Pinkola estés, Clarissa (1996). Mujeres que corren con los lobos, Buenos Aires, Sine Qua Non.

Pollak, Michelle (2006). Memoria, olvido, el silencio, La plata, Al Margen.

Robles, Raquel. "En esta casa no se muere nadie", en La granada, Año 1, n 2, julio 2014, pp. 22-23.

Russell, Diana y Jill Radford (2006 [1976]). Feminicidio: la política del homicidio de mujeres, México, UNAM.

Sarlo, Beatriz (2014 [1987]). “Política, ideología y figuración literaria”, en Balderston, Daniel, Ficción y política. La narrativa argentina durante el proceso militar, Buenos Aires, Eudeba, pp.30-59.

Sarlo, Beatriz (2005). Tiempo pasado. Cultura de la memoria y giro subjetivo, Buenos Aires, Siglo XXI.

Sarlo, Beatriz (2012). "Fin del mundo", en Ficciones argentinas, 33 ensayos, Buenos Aires, Mardulce, 201-205.

Segato, Rita (2014). La escritura en el cuerpo de las mujeres asesinadas en Ciudad Juárez. Tinta limón.

Sosnowski, Saúl (2015 [1997]). “Políticas de la memoria y el olvido”, en Cartografía de las letras hispanoamericanas: tejidos de la memoria,Villa María, EDUVIM, pp.131-149.

\section{Notas}

1 A pesar de que la palabra "femicidio" es la denominación más extendida en Argentina, reconocemos el avance de Marcela Lagarde al formular el neologismo "feminicidio" (como traducción de "femicide" utilizado por Russell y Radford). Acordamos con Lagarde en que "no se trata sólo de la descripción de crímenes que cometen homicidas contra niñas y mujeres, sino de la construcción social de estos crímenes de odio, culminación de la violencia de género contra las mujeres, así como de la impunidad que los configura. Analizado así, el feminicidio es un crimen de Estado, ya que este no es capaz de garantizar la vida y la seguridad de las mujeres en general [...]. El feminicidio, en tanto violencia institucional, se caracteriza también por el no esclarecimiento de los casos investigados" (Lagarde y de los ríos, Marcela (2006 [1976]: 12-13).

2 En ese sentido, la emergencia del término "femicide" por Jill Radford y Diana Russel (y su vulgarización en América Latina por Marcela Lagarde y de los Ríos desde 1992) resulta significativa para considerar las representaciones de los crímenes de violencia contra las mujeres en la literatura latinoamericana. Por un lado, tal como se afirma en este trabajo, un enfoque desde las "narrativas de la dictadura" permite inscribir Chicas muertas en una genealogía sobre el vínculo literatura y violencia en América Latina, que puede remontarse hasta las crónicas de la conquista, incluyendo las novelas de dictadores, las crónicas de la insurgencia armada, la narrativa carcelaria de las dictaduras conosureñas hasta la actual narcoliteratura en Colombia y México (Basile 2015). Por otro lado, entonces, el fenómeno de las muertes y desapariciones de Ciudad Juárez junto con la expansión del concepto de "feminicidio" como clave interpretativa, nos permite pensar en un corpus de la narrativa latinoamericana que explore los crímenes de odio hacia las mujeres y los dispositivos de exterminio incluyendo autores como Carlos Fuentes, Roberto Bolaño, Diego Zúñiga, Gabriela Cabezón Cámara, Sergio Olguín entre otros. La reconstrucción de este corpus en el que sería posible incluir Chicas muertas excede los límites de la presente investigación.

3 Drucaroff explica que en cierta medida este cambio de paradigma estético y político incluye también a los integrantes de lo que ella encuadra en la primera generación de la dictadura, nacidos a partir de 1960: “¿Se puede decir que el tabú del enfrentamiento afectó más la narrativa de la primera generación que la de la segunda? Sí, si se piensa que los más jóvenes publicaron, en general, después de diciembre de 2001. No, si se piensa que algunos de los escritores donde éste está más violentamente transgredido pertenecen a la primera generación, aunque se trate de libros publicados, casi todos, luego de esa fecha" (2011:200).

4 Así, por ejemplo, la narradora introduce las palabras de Sarita Mundín en el recuerdo de su hermana Mirta, como un mensaje a la posteridad: "Su hermana le dijo: Nunca te dejes atropellar por nadie. Vos tenés que hacerte valer. Nunca dejes que un tipo te ponga un dedo encima. Si te pegan una vez, te van a pegar siempre” (2014: 57). 